\title{
Synthesis and Study the Mechanical Properties for New Interpenetrating Polymer Network Based on HBPU/ECA
}

\author{
Firas Jameel Jabbar ${ }^{1}$ \\ \{firas.alassadi@stu.edu.iq $\left.{ }^{1}\right\}$ \\ Department of Pharmacy, Southern Technical University, Basrah, Iraq
}

\begin{abstract}
New types of interpenetrating polymer networks (IPNs) were created in this study, which included highly crosslinked polyurethane (HBPU) with Ethylcynoacrylate (ECA), with different polyurethane percentages (10, 20, 30,40\% wt.). After the success of the preparation process of these polymers, they were identified by ( FTIR ) and $\left({ }^{1} \mathrm{H}\right.$ NMR) spectroscopic to ensure the validity of the prepared polymeric structures. A device ( Instron 5566 ) was used to study the mechanical properties of the prepared polymers and the following functions were obtained: Tensile strength, $\%$ elongation at break, impact strength. The impact of increasing the HBPU prepolymer fraction on the mechanical properties of the interpenetrating polymer network was investigated in this study. Impact strength improved significantly, while tensile strength gradually decreased as the percentage of polyurethane in IPNs rose.
\end{abstract}

Keywords: Hyperbranched polyurethane, HBPU ECA, impact strength, elongation, tensile strength.

\section{Introduction}

The short-chain cyanoacrylate (methyl or ethyl cynoacrylate) compounds are among the groups that belong to vinyl monomers known for their ability to polymerization by free radicals, which is famous for its unique properties, for example, its ability to fast adhesion and high effectiveness, as it has entered multiple industrial applications, especially " super glu" [1-3]. While long-chain cyanoacrylate compounds ( butyl or hexylcyano acrylate ) have been found to have distinguished medical applications in the field of leather and tissue adhesives [4-6]. The World Health Organization has permitted the use of these compounds in the biological and medical fields due to their biodegradability and low toxicity [7-9]. Also, "cyanoacrylate vapour has unique and important uses in forensic science to detect fingerprints by tracing the amino acids present in the fingerprint $[10,11]$. The presence of the double bond in some cyanoacrylate compounds, for example ( allyl 2-cynoacrylate ), gave it an important advantage to enter crosslinking reactions at high temperatures, and this characteristic enabled this type of unsaturated compounds to be used as thermally resistant adhesives $\{12,13]$. Cyanoacrylate polymers have relatively poor thermal stability, and the mechanical properties deteriorate when thermal decomposition occurs, and its polymeric chains break down. The decomposition process often occurs by depolymerization at temperatures lower than the glass transition. Therefore, the idea of the current research is to improve the mechanical properties of cyanoacrylate polymers by preparing an interpenetrating polymer network with polyurethane, which has unique mechanical and thermal properties.[14-16].Smart polymers that can change their shape in response to external conditions and stimuli, such as sunlight, humidity, and $\mathrm{pH}$... have gained "great" attention from the academic and industrial circles, as they have widely entered into medical uses, space, and tissues [17-19]. Polyurethane is considered more popular 
for "smart polymers" uses and has become a "research" topic for many researchers around the world because of its unique, distinct, and comprehensive properties[20-22]. However, the low strength of these polymers will limit their use in areas that require high mechanical properties, for example, materials used in outer space. Many researchers were able to improve the thermal and mechanical properties of polyurethane by adding organic or inorganic materials [23,24].

$\mathrm{Fu}$ et al . successfully developed the thermal properties of polyurethane by adding 1,3,5,7tetrahydroxy adamantane [25]. While A.V et al . prepared a new type of polyurethane with nanotechnology by inserting nanoparticles into the pores of the PU film. The findings revealed that these nanoparticles could boost the polyurethane's blocking effectiveness at the expense of the PU film's memory performance because of these nanoparticles, which are considered one of the types of fillers that work to impede the movement of Polymer chains, which lead to a delay in the process of restoring the shape of the film, and this, in turn, will lead to the depletion of the effect of the shape memory[26]. Therefore, medicating the polymer shape without fillers demands for Shape memory polymers[27-29].

Interpenetrating polymer networks (IPNs) are an overlap of two or more polymers in networks where a partial interlacing on the molecular scale is present in the matrix [30-32]. There is no covalent bonding and therefore the polymers cannot be isolated unless the chemical bonds are crashed [33,34]. Thus, the mixtures of two prepared polymers, networked without any interlacing, are not generally considered to be IPNs, although many researchers have treated them as such IPNs are of different types, viz. sequential, simultaneous, and semi IPNs [35-37]. As their names suggest, sequential IPNs are formed sequentially by more than one IPN in a process, whereas simultaneous IPNs are formed simultaneously. However, semi-IPNs are formed by the polymerisation of a monomer in the presence of a polymer. All the types of IPN listed earlier are found in vegetable oil-based polymers. These IPNs have some advantages over polymer blends or cross-linked polymers[38-40]. Ballestero et colleagues discovered that chemical bonding points formed between two networks of polyurethane and acrylic/ester in interpenetrating polymer networks have a significant effect in minimizing phase separation in the polymeric system. [41]. Chen et al. were able to manufacture a new type of IPNs composite that includes the reciprocal solubility property of polyurethane/epoxy resin of both polymers was utilized to improve their outstanding damping performance [42]. Yu et al. have been preparing a type of IPNs that include polyurethane and epoxy, and they found that these polymers have distinct mechanical properties that include both tensile strength and impact strength. Besides, interpenetrating polymer network can improve the intelligent property of the shape through the formation of the network of entanglement, and therefore IPNs composite is considered an important attractive composite material as many specialized studies have appeared mainly on the mechanical properties and damping properties. While not looking at studies specialized in improving the performance of shape memory[43]. Because polyurethane is highly interlaced, it is considered one of the basic materials that exhibit damping behaviour in ranges of frequency, heat, and distinct thermal stability. Therefore, this type of polymer was used in the manufacture of ships and submarines, as it provided a low cost and improved operational performance compared to metal materials that are used for the same purpose[44]. Therefore, these advantages of polyurethane were taken advantage of to improve some properties of cyanoacrylate by preparing types of (IPNs).

In this work, a new type of interpenetrating polymer network type semi-IPNs has been prepared from mixing hyperbranched polyurethane (HBPU) with the s-triazine unit in the structure, which has a large number of functional groups on its surface, and the other part of IPNs included ethyl cyanoacrylate (ECA), which has a high adhesion strength resulting from the presence of a strong electron-withdrawing nitrile ( $\mathrm{CN}$ ) group and an ester group ( $\mathrm{CO} 2 \mathrm{R}$ ) groups attached to the $\alpha$-carbon of the double bond, but the weak property in this type of polymer is the weak thermal stability, which is close to the glass transition temperature (Tg). To make the HBPU/ ECA IPNs composite, several composition ratios of HBPU prepolymer and ECA were employed. The effect of HBPU content on the mechanical characteristics of IPNs composites was investigated. 


\section{Experimental}

\subsection{Materials and Instrument}

Ethyl cyanoacrylate monomer (, viscosity; $6 \mathrm{cps}$, contains $0-0.3 \%$ hydroquinone as an inhibitor) was obtained from K\&R international. polytetramethylene ether glycol (PTMEG) with Mw of 2000 g mol-1 was obtained from Jining Letian Crafts Co., Ltd, China. MDI (98\% purity) and 1,3,5-Tris (2-hydroxyethyl) isocyanurate (THEIC) were obtained from Sigma-Aldrich (Milwaukee, WI, USA) and were used without any further purification. The IR spectra were registered using a PerkIn-El mer 16 F PCFTIR spectrometer (PerkinElmer Cetus, Norwalk, CT). $\mathrm{CDCl} 3$ as a solvent in an ECX $200-\mathrm{JEOL}{ }^{1} \mathrm{HNMR}$ spectrometer. The Tensile tests were conducted as specified by ASTM D638, while the flexural strength test was conducted as specified by ASTM -D790-10. An Instron- 5566 (Instron, Canton. MA.USA) was used for the tensile and flexural tests e film specimens were made in a dog bone shape according to ISO.5272./1BB standards, with dimensions of $38 \mathrm{~mm} \times 2 \mathrm{~mm}$ (centre) x $0.4 \mathrm{~mm}$. To achieve average values, at least five specimens were tested. Multimode3 Atomic Force (AFM) microscope(Brooke. the USA).

\subsection{Preparation of HBPU/ECA IPNs}

Scheme 1 shows the detailed synthesis procedure for the HBPU/ ECA IPNs hybrid. To begin, ( PIMEC ) was put to a reaction vessel with three necks, to which substance ( MDI ) was added in the following molar ratios (3: 7) and the reaction was stirred for 2 hours under a nitrogen atmosphere at a temperature of $\left(60{ }^{\circ} \mathrm{C}\right)$. Then, according to the following molar ratio $(1: 8)$, a mixture of ( THEIC ) and ( MDI ) is made, and it is introduced to the reaction vessel with three necks and mixed for 5 hours at $\left(80^{\circ} \mathrm{C}\right)$ to obtain HBPU prepolymer. After the period for forming the (pre-prepared polymer) has passed, an equivalent amount of (ECA) is added to the (prepolymer) and thoroughly mixed. Finally, ( HBPU/ECA) is poured into the meld and treated in the oven at a temperature of $\left(130^{\circ} \mathrm{C}\right)$ for 8 hours for the curing process to be done accurately. The HBPU/ECA IPNs with 10, 20, 30, 40 wt \% HBPU were defined as IPN-1, IPN-2, IPN-3, IPN-4, respectively.

Table 1. Show the ratio of component HBPU, ECA in IPNs

\begin{tabular}{|l|l|l|l|l|}
\hline IPNs & IPN-1 & IPN-2 & IPN-3 & IPN-4 \\
\hline$\%$ HBPU/ECA & $10 / 90$ & $20 / 80$ & $30 / 70$ & $40 / 60$ \\
\hline
\end{tabular}




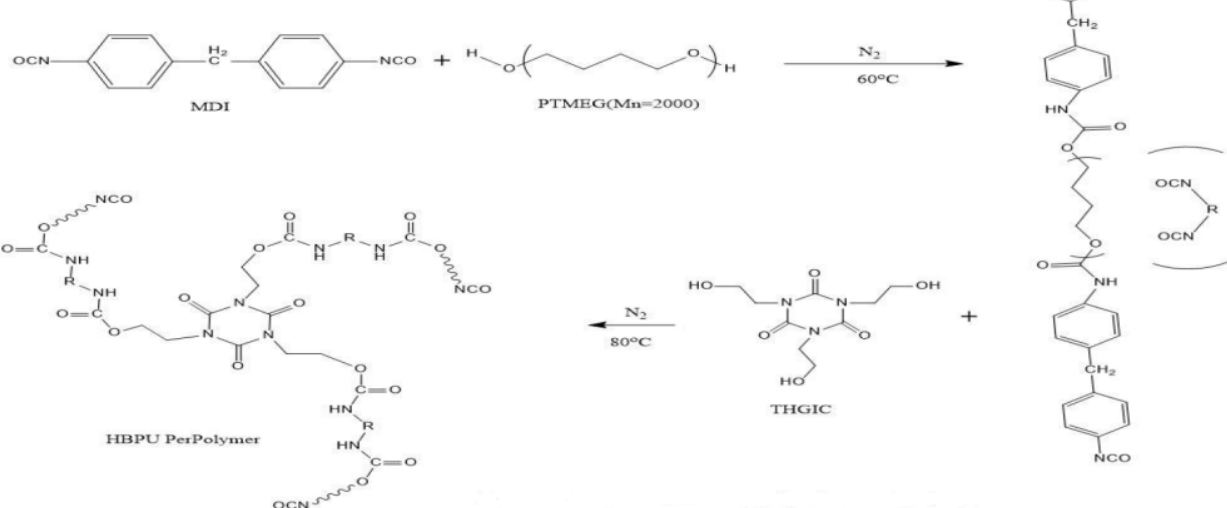

Scheme 1. Detailed synthesis route of the HBPU prepolymer

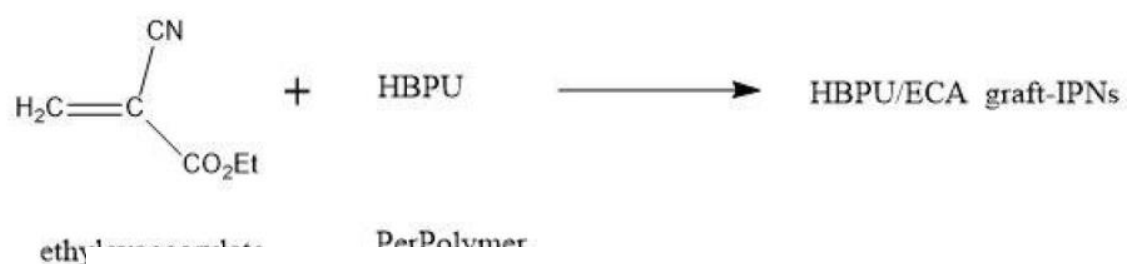

Scheme 2. Detailed synthesis of the HBPU/ECA IPNs

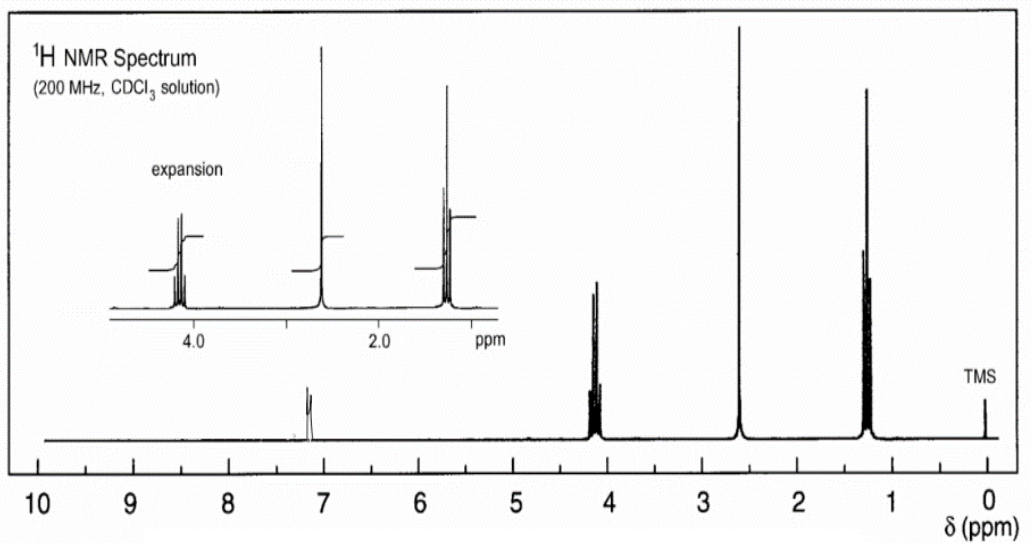

Fig 1. ${ }^{1} \mathrm{HNMR}$ curve of HBPU prepolymer.

To confirm the formation of the interpenetrating polymer network, spectroscopy FTIR and $\mathrm{H}^{1}$ NMR were adopted to document the validity of the formed polymers. The ${ }^{1} \mathrm{H}$ NMR spectrum of the HBPU prepolymer is shown in Fig 1. Two peaks appear at $(1.25 \delta)$ and $(2.70 \delta)$, which are attributed to $-\mathrm{CH}_{2}-$ and $-\mathrm{O}-\mathrm{CH}_{2}-$ in PTMEG respectively, while prominent bands appear at $(4.1 \delta)$ attributable to-- $\mathrm{CH}_{2}$ which connected with a triazine ring, and this confirms the occurrence of the formation HBPU prepolymer as a result of the reaction between NCO group in MDI with the terminal hydroxyl group in compound THELC as shown in scheme (1). As for the bands appearing in position $(7.1 \delta)$ they belong to the protons of the benzene 
ring located in MDI. Also, to prove the formation of the interpenetrating polymer networks that include ECA and HBPU, the FTIR technique was used to confirm the validity of the formation of these polymers. Fig 2 shows the spectra of three samples, which are respectively ( ECA), ( HBPU), and ( IPN-4). The appearance of the stretch band at $\mathrm{cm}^{-1}$ for the group $\left(\mathrm{CH}=\mathrm{CH}_{2}\right)$ in the monomer spectrum ECA and its disappearance in the spectrum IPNs proves the polymerization of the monomer and the formation of IPNs. Two peaks of HBPU prepolymer were identified, located at $3400 \mathrm{~cm}^{-1}$ and $1750 \mathrm{~cm}^{-1}$, belonging to the group $-\mathrm{NH}$ stretching vibration and strong stretching $\mathrm{C}=\mathrm{O}$, respectively, and this is proof of the generation of urethane linkage, in addition to a peak at $2300 \mathrm{~cm}^{-1}$ attributed to group (NCO) terminal unreacted of HBPU prepolymer, the disappearance of this group when preparing all interpenetrating polymer networks confirms the success and validity of the preparation method.

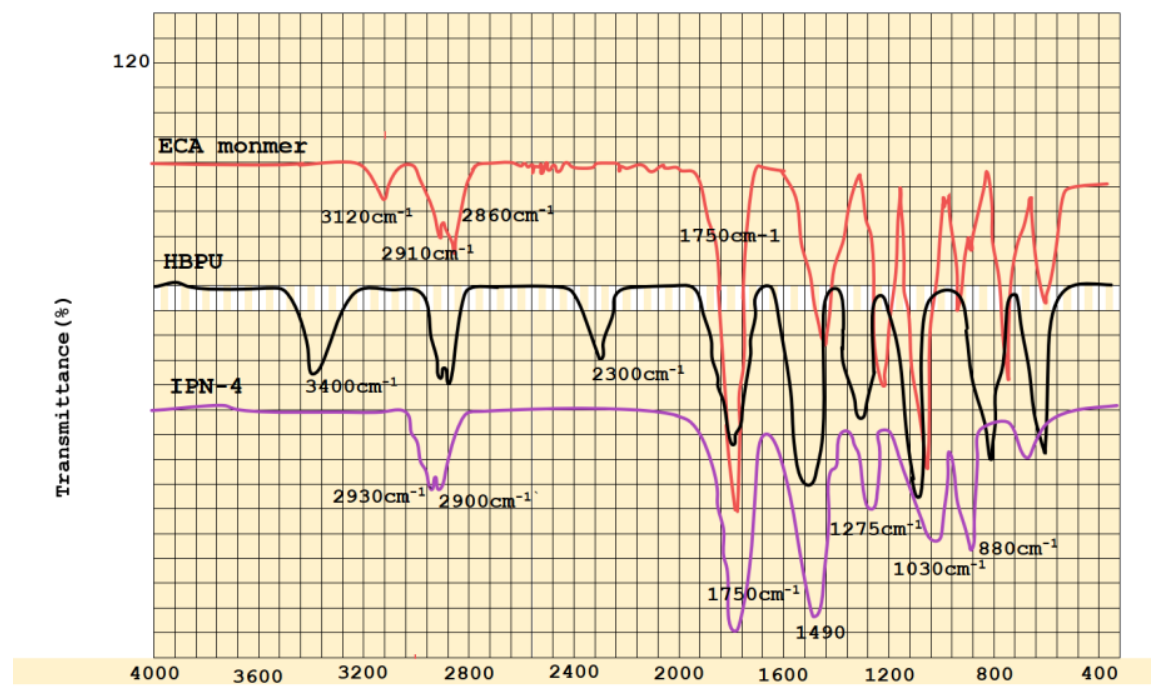

Fig 2. FTIR spectrum of ECA monmer, HBPU prepolymer and IPN-4.

\subsection{Mechanical Properties}

In polymers, stress-strain relationships are called dynamic dependencies and are not linear. The stress-strain curve was used to assess tensile characteristics (tensile strength at yield, impact strength, \% elongation, and flexural stress ). The (stress-strain) curve of IPN-1, IPN-2, IPN-3, IPN-4, and HBPU was shown in Fig 1 as an example of the effect of HBPU on the mechanical properties of IPNs based on HBPU/ECA. The tensile strength (TS) data of the various IPNs prepared in this study are shown in Fig 2. As DMTA data for IPNs is analysed, it can be shown that increasing HBPU causes a significant decrease in tensile strength from $51 \mathrm{MPa}$ to $20 \mathrm{MPa}$ and flexure stress from 481.4 MPa to 59.6 MPa, respectively. For all IPNs, the data indicate a slight increase in the Impact strength and a significant increase in \% elongation at break from 15 to 65 . This behaviour may be explained by a rise in interpenetration network formation.

Table 2. mechanical properties data of HBPU/ECA IPNs with different \%wt.

\begin{tabular}{|c|c|c|c|c|}
\hline Samples & $\begin{array}{l}\text { Tensile strength } \\
\text { (MPa) }\end{array}$ & $\begin{array}{l}\% \text { Elongation at } \\
\text { break }\end{array}$ & $\begin{array}{l}\text { Impact strength } \\
\mathrm{KJ} / \mathrm{m}^{2}\end{array}$ & $\begin{array}{l}\text { Flexure stress } \\
\text { MPa }\end{array}$ \\
\hline IPN-1 & 51 & 15 & 3.88 & 81.4 \\
\hline IPN-2 & 45 & 25 & 3.98 & 70.2 \\
\hline IPN-3 & 27 & 50 & 4.12 & 65.2 \\
\hline IPN-4 & 20 & 65 & 4.26 & 59.6 \\
\hline ECA polymer & 75 & 10 & 3.84 & 66.0 \\
\hline
\end{tabular}


Another cause is the creation of crosslinking sites between HBPU and ECA, which makes the polymer chains less prone to slip at room temperature due to external forces. Elongation at break increases as HBPU content in HBPU/ECA IPNs increases, whereas tensile strength and Flexure stress steadily decrease. The results are like those seen in AFM's phase diagram Fig (9), indicating that the continuous hard phase of ECA in IPN-1 causes brittleness and that the elongation at break increase as the HBPU content rises. However, as HBPU content is increased, the number of PU domains in the composites grows, and as is well known, increasing the amount of polyurethane with a soft molecular chain reduces tensile strength. These findings imply that forming crosslinking sites between HBPU and ECA can improve mechanical strength and elastic modulus, which is dependent on the ECA/HBPU \%wt. It also lays the groundwork for the HBPU-based IPNs shape memory polymer to have good mechanical properties. The technique (AFM) is one of the important and common techniques in distinguishing the phase separation in different polymeric materials and this is evident in the different shapes of the overlapping in interpenetrating polymer network .this appears in Fig (9A-D), which represents (IPN1-4), where we note that the incandescent parts represent the solid phase while the dark parts represent the soft phase. In Fig (9A), which shows the special morphology of the polymer (IPN-1) with a polyurethane ratio of $10 \%$, there is a large overlap and compatibility between polyurethane and the monomer Ethyl Cynoacrylate and the appearance of the glowing parts representing the solid phase, which are about $(10 \mathrm{~nm})$ dimensions, while the compatibility begins to decay at increasing the proportion of polyurethane, where the dimensions are about (60nm), $150 \mathrm{~nm}$ and $200 \mathrm{~nm}$ for each of IPN2, IPN3 and IPN4 respectively.

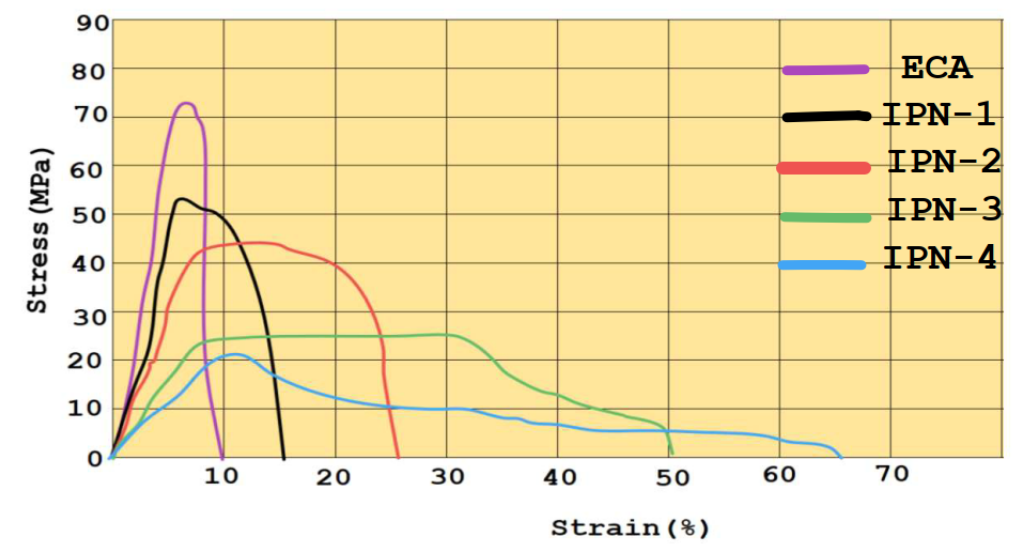

Fig 3. The representative stress-strain curves of HBPU/ECA IPNs with different composition ratios. 


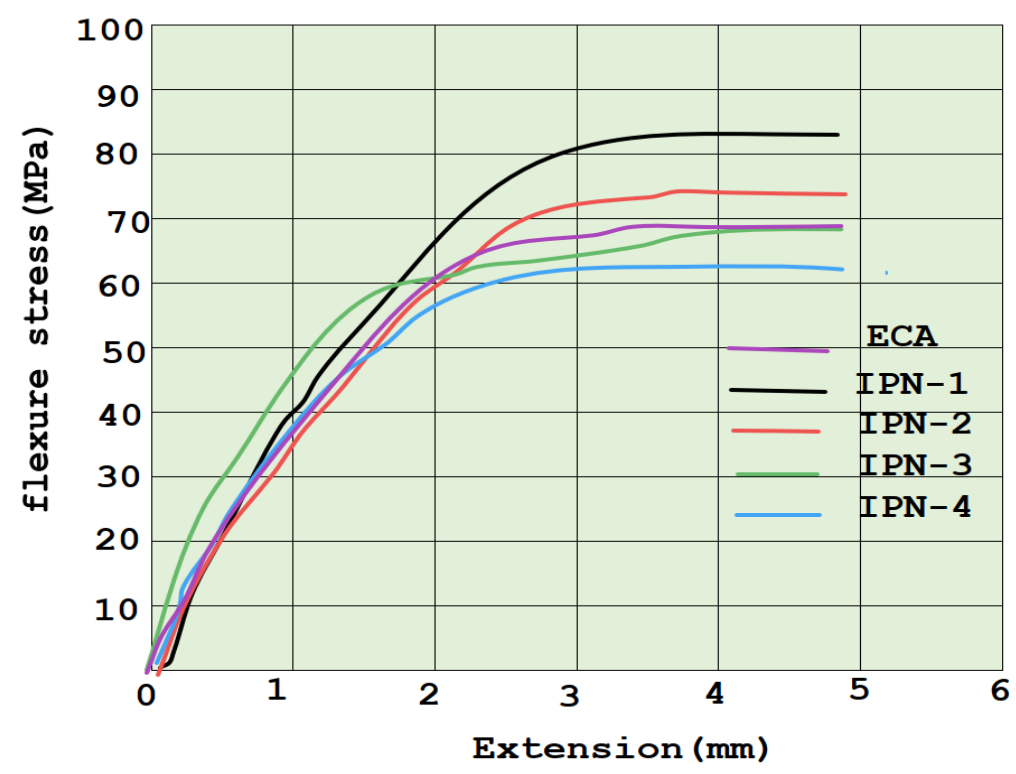

Fig 4. Show the flexture stress with Extension for IPNs.

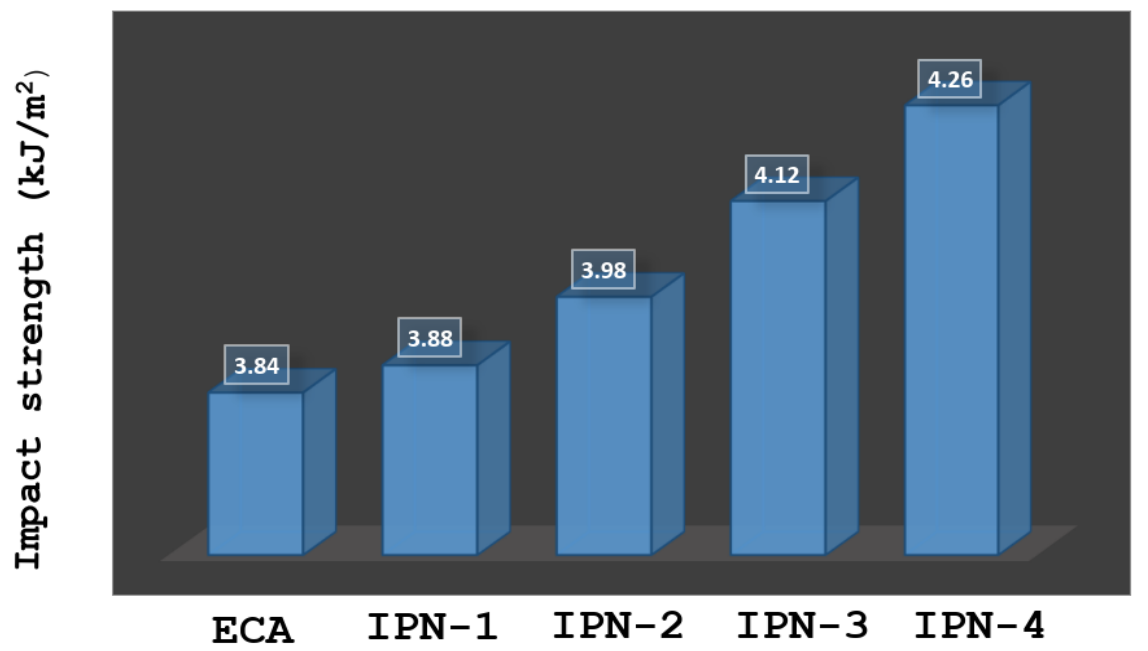

Fig 5. Show the Impact strength for ECA \& IPNs. 


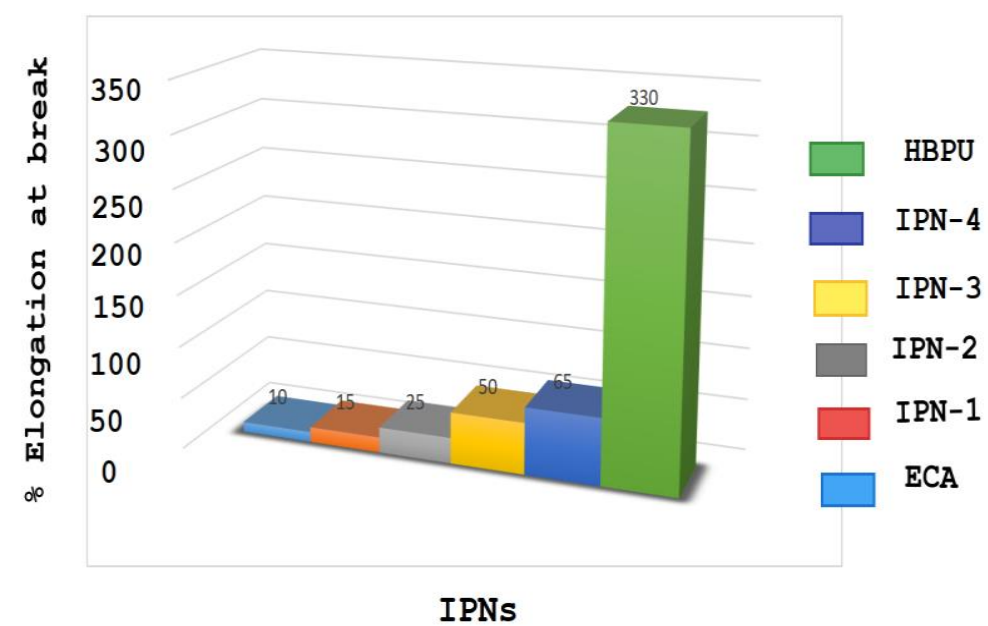

Fig 6. Show the \% Elongation at break for HBPU, ECA \& IPNS.

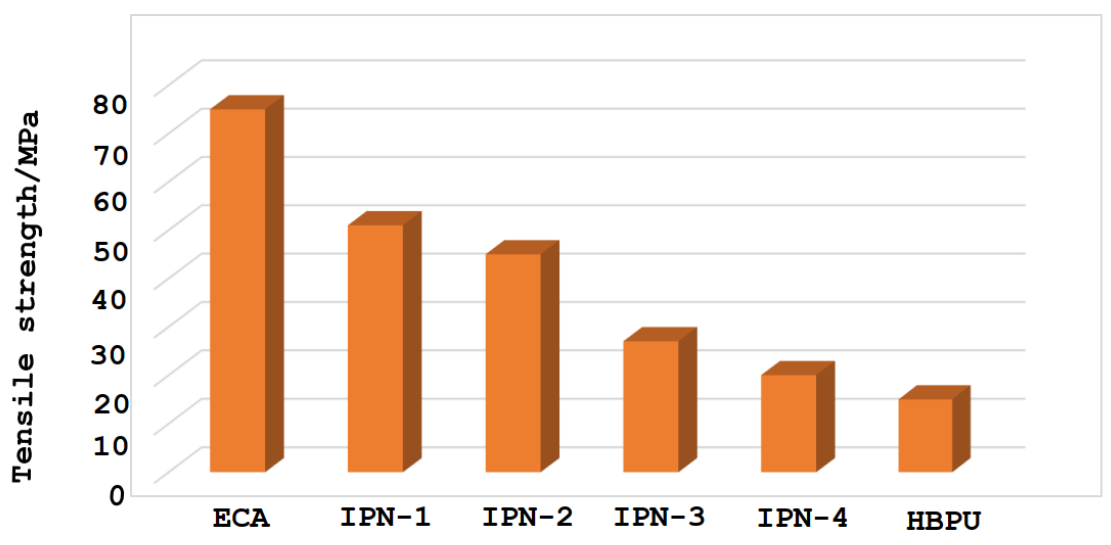

Fig 7. Show the Tensile strength for ECA, HBPU \& IPNs

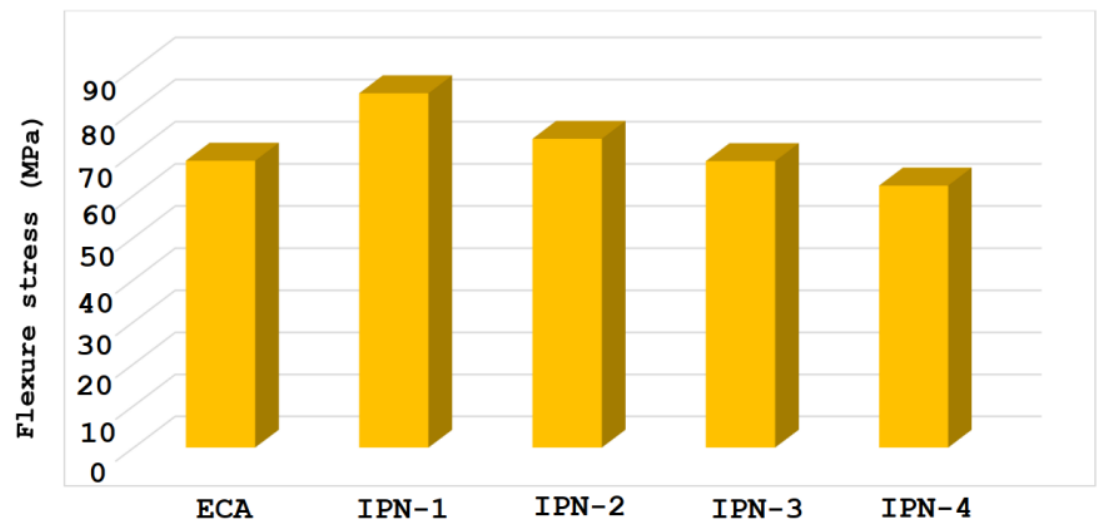

Fig 8. Show the Fleure stress for ECA \& IPNs 

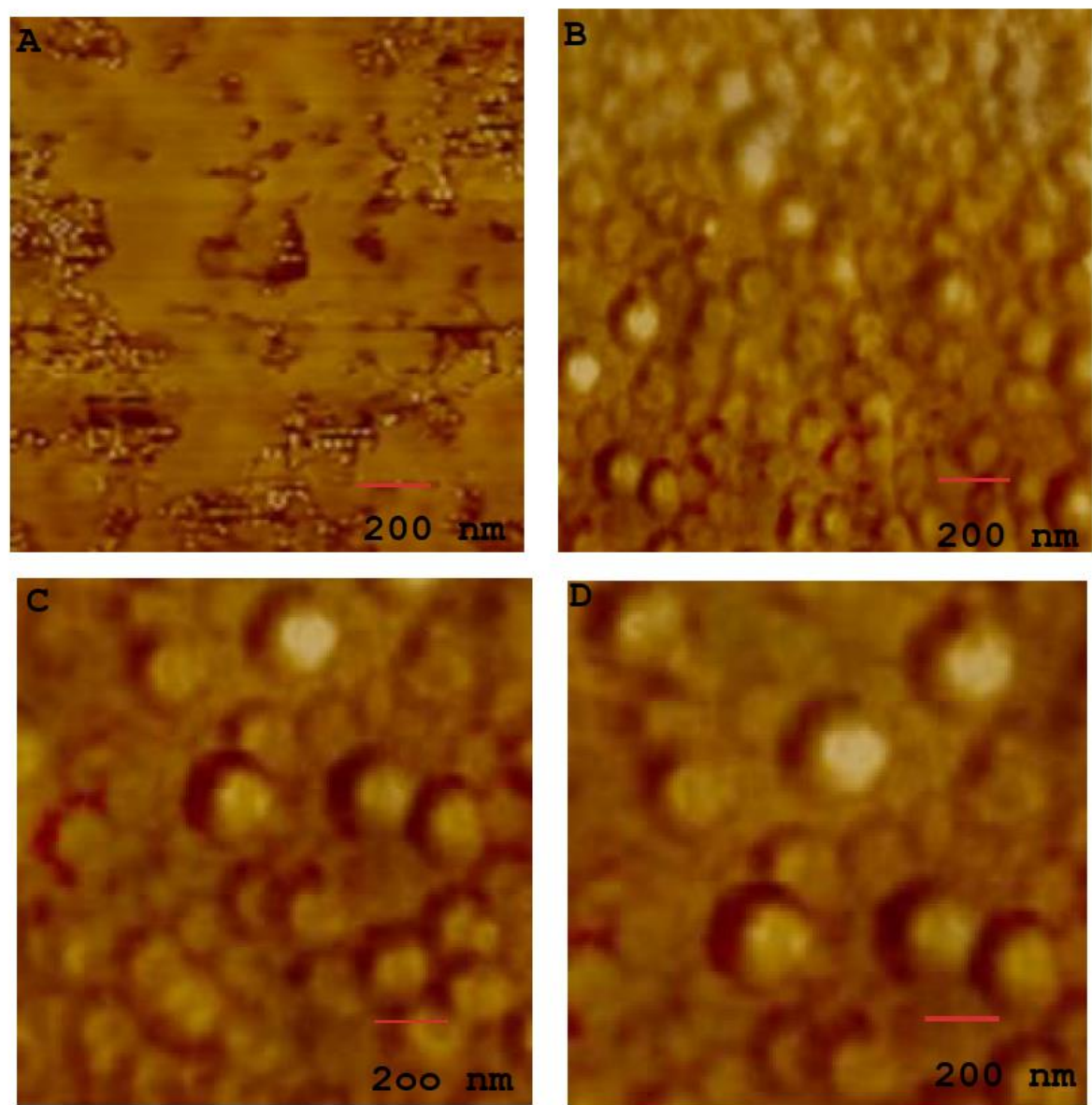

Fig 9. AFM micrographs of the IPNs samples: (A) IPN-1 and (B) IPN-2 (C) IPN -3 (D) IPN-4.

\section{Conclusions}

IPNs were produced by grafting HBPU and ECA together, resulting in an HBPU prepolymer with a triazinyl ring structure. The effects of the HBPU percentage on the mechanical properties of the IPNs were investigated. We can conclude that there are some considerable trends. As a result, the elastomeric IPN-4 sample indicated the highest value of impact strength $\left(4.26 \mathrm{~kJ} / \mathrm{m}^{2}\right.$ ) and the value of (65) for \%elongation at break. . A decrement of modulus and tensile strength with a resultant increment of elongation for the elastomeric samples from (51 MPa) for IPN-1 to (20 MPa) for IPN-4 were observed.

\section{References}

[1]Klemarczyk, P.; Guthrie, J. Advances in anaerobic and cyanoacrylate adhesives. In advances in Structural Adhesive Bonding, 1st ed.; Dillard, D., Ed.; Woodhead Publishing Limited: Cambridge, UK, 2010; pp. 96-131, ISBN 978-1-84569-435-7.

[2] Shantha, K.L.; Thennarasu, S.; Krishnamurti, N. Developments and applications of cyanoacrylate adhesives.J. Adhes. Sci. Technol. 1989, 3, 237-260. [CrossRef]

[3] Fink, J.K. Chapter 13-Cyanoacrylates. In Reactive Polymers Fundamentals and Applications, 2nd ed.; Fink, J.K., Ed.; Elsevier: London, UK, 2013; pp. 317-330, ISBN 978-1-4557-3149-7. 
[4] Singer, A.J.; Thode, H.C., Jr. A review of the literature on octylcyanoacrylate tissue adhesive. Am. J. Surg.(2004), 187, 238-248. [CrossRef] [PubMed].

[5] .Singer, A.J.; Quinn, J.V.; Hollander, J.E. The cyanoacrylate topical skin adhesives. Am. J. Emerg. Med. 2008,26 , 490-496. [CrossRef] [PubMed].

[6] Shivamurthy, D.M.; Singh, S.; Reddy, S. Comparison of octyl-2-cyanoacrylate and conventional sutures in facial skin closure. Natl. J. Maxillofac. Surg. 2010, 1, 15-19. [CrossRef] [PubMed]

[7] .Hynes, S.J. Biomedical applications of 2-cyanoacrylates. Irish Chem. News 2009, 25, 24-28.

[8] Nicolas, J.; Couvreur, P. Synthesis of poly(alkyl cyanoacrylate)-based colloidal nanomedicines. Wiley Interdiscipl. Rev. Nanomed. Nanobiotechnol. 2009, 1, 111-127. [CrossRef] [PubMed]

[9] Vauthier, C.; Dubernet, C.; Fattal, E.; Pinto-Alphandary, H.; Couvreur, P. Poly(alkylcyanoacrylates) as biodegradable materials for biomedical applications. Adv. Drug Deliv. Rev. 2003, 55, 519-548. [CrossRef].

[10] 17. Bumbrah, G.S. Cyanoacrylate fuming method for detection of latent fingermarks: a review. Egypt J. Forensic Sci. 2017, 7, 4. [CrossRef] [PubMed]

[11] Tahtouh, M.; Kalman, J.R.; Reedy, B.J. Synthesis and characterization of four alkyl 2-cyanoacrylate monomers and their precursors for use in latent fingerprint detection. J. Polym. Sci. Part A Polym. Chem. 2011, 49, 257-277. [CrossRef]

[12]Graf, A.; McDowell, A.; Rades, T. Poly(alkycyanoacrylate) nanoparticles for enhanced delivery of therapeutics-Is there real potential? Expert Opin. Drug Deliv. 2009, 6, 371-387. [CrossRef] [PubMed]

[13] Yordanov, G. Poly(alkyl cyanoacrylate) nanoparticles as drug carriers: 33 years later. Bulg. J. Chem. 2012, 1,61-73.

[14] Arias, J.L.; Gallardo, V.; Ruiz, M.A. Chapter 4-Multifunctional anticancer nanomedicine based on a magnetically responsive cyanoacrylate polymer. Methods in Enzymol. 2012, 508, 61-88. [CrossRef]

[15]Bumbrah, G.S. Cyanoacrylate fuming method for detection of latent fingermarks: a review. Egypt J. Forensic Sci. 2017, 7, 4. [CrossRef] [PubMed]

[16] Tahtouh, M.; Kalman, J.R.; Reedy, B.J. Synthesis and characterization of four alkyl 2-cyanoacrylate monomers and their precursors for use in latent fingerprint detection. J. Polym. Sci. Part A Polym. Chem. 2011, 49,257-277. [CrossRef]

[17] Liu.C, Qin.H, Mather.P.T, Review of progress in shape-memory polymers, J.

Mater. Chem. 17 (16) (2007) 1543.

[18] Sun.L, Huang.W.M, Ding. Z, Zhao. Y, Wang .C.C, Purnawali . H, Tang . C, Stimulus-responsive shape memory materials: A review, Mater Des. 33 (2012) 577-640.

[19] Hu. J, Zhu . Y, Huang . H, Lu . J , Recent advances in shape-memory polymers:Structure, mechanism, functionality, modeling and applications, Prog. Polym. Sci.37 (12) (2012) 1720-1763.

[20] Sharmin, E.; Zafar, F. Polyurethane: An Introduction; InTech: London, UK, 2012.

[21] Polyurethane Global Market Size Forecast 2021. Available online: https://www.statista.com/statistics/720449/global-polyurethane-market-size-forecast/ (accessed on 13 September 2018).

[22] Polyurethane Production, Pricing and Market Demand. Available online: https://www.plasticsinsight.com/resin-intelligence/resin-prices/polyurethane/ (accessed on 13 September 2018).

[23] Polo.M, Sponton. M, Jaramillo. F, Estenoz .D, Meira. G (2018) Linear segmented polyurethanes: I. A kinetics study. J Appl Polym Sci 135(4): 45747.

[24] Akbulut .H, Yoshida. Y, Yamada. S, Endo .T (2019) Synthesis and physical properties of poly(urethane)s using vicinal diols derived from acrylate and styrene monomers. J Polym Sci Part A, Polym Chem 57(7): 799-805.

[25] Fu. S, Zhu. J, Zou . F, Zeng . Z, Chen . S , A novel adamantane-based polyurethane with shape memory effect, Mater. Lett. 229 (2018) 44-47.

[26] Menon .A. V, Madras . G, Bose . S, Shape memory polyurethane nanocomposites with porous architectures for enhanced microwave shielding, Chem. Eng. J. 352 (2018) 590-600.

[27] Meng .H , Li . G , A review of stimuli-responsive shape memory polymer composites, Polymer 54 (9) (2013) 2199-2221.

[28] Hager. M . D, Bode. S, Weber. C, Schubert. U. S, Shape memory polymers: Past, present and future developments, Prog. Polym. Sci. 49-50 (2015) 3-33.

[29] Wang. L, Yang. X, Chen. H, Gong. T, Li . W, Yang. G, Zhou . S, Design of tripleshapemmemory polyurethane with photo-cross-linking of Cinnamon groups, ACS Appl. Mater. Inter. 5 (21) (2013) 10520-10528. 
[30] Chen, S., Wang, Q., Wang, T., 2011. Hydroxy-terminated liquid nitrile rubber modified castor oil based polyurethane/epoxy IPN composites: Damping, thermal and mechanical properties. Polym. Test. 30, 726-731.

[31] Chen, S., Wang, Q., Pei, X., Wang, T., 2010. Dynamic mechanical properties of castor oil based polyurethane/epoxy graft interpenetrating polymer network composites. J. Appl. Polym. Sci. 118, 11441151.

[32] Sangermano M, Cook WD, Papagna S, Grassini S (2012) Hybrid UV-cured organic-inorganic IPNs. Eur Polym J 48:1796-1804.

[33] Hoffman, T., Khademhosseini, A., and Langer, R. (2019). Chasing the paradigm: clinical translation of 25 years of tissue engineering. Tissue Eng-Part A 25: 679-687.

[34] Dragan, E.S. (2014). Design and applications of interpenetrating polymer network hydrogels. A review. Chem. Eng. J. 243: 572-590.

[35] Kaczmarek, H., Vukovil-Kwiatkowska, I.,"Preparation and characterization of interpenetrating networks based on polyacrylates and poly (lactic acid)" eXPRESS Polymer Letters, 6, 1, 2012, 78-94.

[36] Shivashankar, M., Mandal, B., "A Reviewon Interpenetrating Polymer Network",Int JPharm Pharm Sci, 4, Suppl 5, 2012, 1-7.

[37] Kamal, M., "Camphor and poly (antimony acrylate) based interpenetrating network: Synthesis and Characterization",India Journal of Chemical Technolog , 18, July2018, pp. 284-290.

[38] Pan .J, Zhu . L, Han .J , and Hickner. M . A , "Mechanically tough and chemically stable anion exchange membranes from rigid-flexible semi-interpenetrating networks," Chemistry of Materials, vol. 27, no. 19, pp. 6689-6698, 2015.

[39] Lin . J, Yan . X, He . J , "Thermoplastic interpenetrating polymer networks based on polybenzimidazole and poly (1, 2-dimethy-3-allylimidazolium) for anion exchange membranes," Electrochimica Acta, vol. 257, pp. 9-19, 2017.

[40] Wang .Y, Wan . J, Wang . D , Wang . J, Wang . L and Feng . F "Preparation and characterization of a semi-interpenetrating network alkaline anion exchange membrane," Fibers and Polymers, vol. 19, no. 1, pp. 11-21, 2018.

[41] Ballestero .R, Sundaram .B.M, Tippur . H.V , Auad . M.L, Sequential graft-inter-penetrating polymer networks based on polyurethane and acrylic/ester copolymers,eXPRESS Polym. Lett. 10 (3) (2016) 204-215.

[42] Chen .S ,Wang . Q , Pei .X , Wang . T, Dynamic mechanical properties of castor oil-based polyurethane/epoxy graft interpenetrating polymer network composites, J.Appl. Polym. Sci. (2010) n/an/a.

[43] Yu .P, Li . G, Zhang . L, Zhao . F, Chen . S, Dmitriev . A . I, Zhang .G, Regulating microstructures of interpenetrating polyurethane-epoxy networks towards high-per-formance waterlubricated bearing materials, Tribol. Int. 131 (2019) 454-464.

[44] Mouritz A.P., Gellert E., Burchill P., Challis K.: Composite Structures 2001, 53, 21. 